\title{
THERMODYNAMIC PROPERTIES OF CITRIC ACID AND THE SYSTEM CITRIC ACID-WATER
}

\author{
C.G. DE KRUIF, J.C. VAN MILTENBURG, A.J.J. SPRENKELS, G. STEVENS, \\ W. DE GRAAF and H.G.M. DE WIT \\ Department of General Chemistry, Chemical Thermodynamics Group, State University of \\ Utrecht, De Uithof, 3508 TB Utrecht (The Netherlands)
}

(Received 14 April 1982)

\section{ABSTRACT}

The binary system citric acid-water has been investigated with static vapour pressure measurements, adiabatic calorimetry, solution calorimetry, solubility measurements and powder X-ray measurements. The data are correlated by thermodynamics and a large part of the phase diagram is given. Molar heat capacities of citric acid are given from 90 to $330 \mathrm{~K}$ and for citric acid monohydrate from 120 to $300 \mathrm{~K}$. The enthalpy of compound formation $\Delta_{\text {com }} H(298.15 \mathrm{~K})=(-11.8 \pm 1) \mathrm{kJ} \mathrm{mole}^{-1}$.

\section{INTRODUCTION}

Many organic substances occurring in nature form hydrates. This means they can crystallize stoichiometrically with one or more moles of water, dependent on conditions of pressure and temperature. This hydrate formation is reflected in the phase diagram of the binary system 'organic substance-water', from which the regions of phase stability can be read.

As hydrates of organic substances play an important role in physiology and pharmacology, biological research groups show an increasing interest in their thermodynamic properties. Recently, our group received requests from three different research disciplines for the determination of properties such as solubility, stability region, transition temperatures and transition enthalpies for hydrates of calcium oxalate, citric acid and theophylline.

Our group has for many years been occupied with the determination of thermodynamic properties of organic substances by means of calorimetry and vapour pressure measurements. Apart from this, we are working on lattice energy determinations and calculations (by the atom-atom potential method). As in hydrates the water molecules appear to be almost exclusively bonded by hydrogen bridges, a comparison of their lattice energy calculation 
with that for the corresponding anhydrates may contribute to a better understanding in the matter of hydrogen bridge bonding.

While working on the hydrates, we decided to study one binary system in greater detail, which could then be used as a reference system both for theoretical and experimental aspects. Because certain relations exist between a number of experimentally determined quantities, obtained by different methods, this fact enables us to make an cstimation of the accuracy and consistency of the methods applied.

In this paper, a thermodynamic description of the citric acid-water binary system is given, with special attention to the phase behaviour of the stoichiometric crystalline hydrate. In addition, we will give a description of the experimental methods used and a discussion of the results obtained.

\section{THERMODYNAMIC DESCRIPTION}

In view of the (limited) mutual solubility, we may predict that the $T-x$ phase diagram of the solid-liquid phases shows eutectic behaviour. Due to compound formation, the phase diagram will contain a second three-phase line at the peritectic temperature. So at constant pressure, the solid-liquid phase diagram will have the form of Fig. 1(a). Experimentally, the diagram can be obtained from the solubility of citric acid in water and from the three-phase line temperatures.

In addition to the solid-liquid phase diagram, we measured (at least in part) the solid-vapour and liquid-vapour equilibria. Because citric acid is less volatile than water by at least a factor of $10^{9}$ at temperatures below 373 $\mathbf{K}$, we assume water to be the only species present in the vapour phase. The system citric acid water-water vapour is monovariant and the $P-x$ diagrams
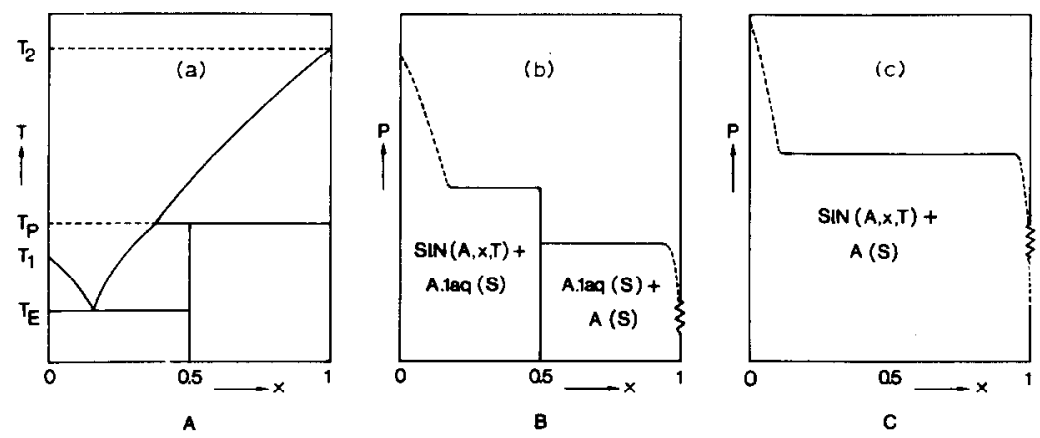

Fig. 1. (a) General features of the expected phase diagram. (b) and (c) Sketched $P-x$ diagrams for temperatures below and above the peritectic temperature, respectively. 
will be as sketched in Fig. 1(b) and (c). Apart from these phase diagrams, we are particularly interested in the change in values of the thermodynamic functions, when a point in the diagram is realized by mixing the pure components in appropriate quantities and at appropriate temperatures. Because we also measured some equilibria along the two-phase lines, we will write out these 'phase reactions' in a general form together with some auxilliary equations.

\section{GENERAL EQUATIONS}

Citric acid will be denoted by $A$, the hydrate by A.laq, and a saturated solution of citric acid in water by $\sin (A, x, T)$ meaning that the solution contains $(1-x)$ moles of water and $x$ moles of citric acid at temperature $T$. The diluted solution is defined by $\sin \left(\mathrm{nH}_{2} \mathrm{O}, \mathrm{A}, \mathrm{T}\right)$, containing 1 mole of $\mathrm{A}$ and $n(>=500)$ moles water. For temperatures below the peritectic temperature, we may write

$$
\mathrm{A}(\mathrm{s})+\mathrm{H}_{2} \mathrm{O}(\mathrm{l}) \rightarrow \mathrm{A} . \mathrm{laq}(\mathrm{s})
$$

$\mathrm{A} .1 \mathrm{aq}(\mathrm{s}) \rightleftarrows \mathrm{A}(\mathrm{s})+\mathrm{H}_{2} \mathrm{O}(\mathrm{v})$

$$
x \mathrm{~A} .1 \mathrm{aq}(\mathrm{s})+(1-2 x) \mathrm{H}_{2} \mathrm{O}(1) \rightarrow \mathrm{s} \ln (\mathrm{A}, \mathrm{x}, \mathrm{T})
$$

$x \mathrm{~A}(\mathrm{~s})+(1-x) \mathrm{H}_{2} \mathrm{O}(1) \rightarrow \mathrm{s} \ln (\mathrm{A}, \mathrm{x}, \mathrm{T})$

A. $1 \mathrm{aq}(\mathrm{s})+(n-1) \mathrm{H}_{2} \mathrm{O}(1) \rightarrow \sin \left(\mathrm{nH}_{2} \mathrm{O}, \mathrm{A}, \mathrm{T}\right)$

$\mathrm{A}(\mathrm{s})+n \mathrm{H}_{2} \mathrm{O}(\mathrm{l}) \rightarrow \mathrm{s} \ln \left(\mathrm{nH}_{2} \mathrm{O}, \mathrm{A}, \mathrm{T}\right)$

At the peritectic or transition temperature

$$
(1-x)^{-1}\{(1-x) \mathrm{A} . \mathrm{laq}(\mathrm{s}) \rightleftarrows(1-2 x) \mathrm{A}(\mathrm{s})+\mathrm{s} \ln (\mathrm{A}, \mathrm{x}, \mathrm{T})\}
$$

Above the peritectic temperature

$$
(1-x)^{-1}\left\{\sin (\mathrm{A}, \mathrm{x}, \mathrm{T}) \rightleftharpoons x \mathrm{~A}(\mathrm{~s})+(1-x) \mathrm{H}_{2} \mathrm{O}(\mathrm{v})\right\}
$$

We will also make use of

$$
\mathrm{H}_{2} \mathrm{O}(\mathrm{l}) \Rightarrow \mathrm{H}_{2} \mathrm{O}(\mathrm{v})
$$

Except for eqns. (a) and (i), we have determined the enthalpy and/or entropy changes of the respective phase reactions. By suitable combination of these quantities, others can be calculated. We will illustrate this on the enthalpy changes but it can be done for the entropy likewise. 


\section{ENTHALPY OF COMPOUND FORMATION}

$\Delta_{\mathrm{com}} H_{\mathrm{a}}=H^{*}(\mathrm{~A} .1 \mathrm{aq}, \mathrm{s})-H^{*}(\mathrm{~A}, \mathrm{~s})-H^{*}\left(\mathrm{H}_{2} \mathrm{O}, 1\right)$

This can be found from the following quantities determined experimentally.

$$
\begin{aligned}
& \Delta_{\text {sitl }} H_{\mathrm{d}}-\Delta_{\text {sat }} H_{\mathrm{c}}=H(\operatorname{s} \ln \mathrm{A}, \mathrm{x}, \mathrm{T})-x H^{*}(\mathrm{~A}, \mathrm{~s})-(1-x) H^{*}\left(\mathrm{H}_{2} \mathrm{O}, \mathrm{l}\right) \\
& -H(\sin \mathrm{A}, \mathrm{x}, \mathrm{T})+x H^{*}(\mathrm{~A} .1 \mathrm{aq}, \mathrm{s})+(1-2 x) H^{*}\left(\mathrm{H}_{2} \mathrm{O}, 1\right) \\
& x \Delta_{\mathrm{com}} H_{\mathrm{a}}=x H^{*}(\mathrm{~A} .1 \mathrm{aq}, \mathrm{s})-x H^{*}(\mathrm{~A}, \mathrm{~s})-x H^{*}\left(\mathrm{H}_{2} \mathrm{O}, 1\right) \\
& \Delta_{\text {com }} H_{\mathrm{a}}=H^{*}(\mathrm{~A} .1 \mathrm{aq}, \mathrm{s})-H^{*}(\mathrm{~A}, \mathrm{~S})-H^{*}\left(\mathrm{H}_{2} \mathrm{O}, 1\right) \\
& \Delta_{\text {vap }} H_{\mathrm{i}}-\Delta_{\text {vap }} H_{\mathrm{b}}=H^{*}\left(\mathrm{H}_{2} \mathrm{O}, \mathrm{v}\right)-H^{*}\left(\mathrm{H}_{2} \mathrm{O}, \mathrm{l}\right) \\
& -H^{*}(\mathrm{~A}, \mathrm{~s})-H^{*}\left(\mathrm{H}_{2} \mathrm{O}, \mathrm{v}\right)+H^{*}(\mathrm{~A} .1 \mathrm{aq}, \mathrm{s}) \\
& \Delta_{\text {com }} H_{\mathrm{a}}=H^{*} \text { (A.laq, s) }-H^{*}(\mathrm{~A}, \mathrm{~s})-H^{*}\left(\mathrm{H}_{2} \mathrm{O}, \mathrm{l}\right) \\
& \Delta_{\mathrm{sol}} H_{\mathrm{f}}-\Delta_{\mathrm{sol}} H_{\mathrm{e}}=H\left(\mathrm{~s} \ln , \mathrm{nH}_{2} \mathrm{O}, \mathrm{A}, \mathrm{T}\right)-H^{*}(\mathrm{~A}, \mathrm{~S})-n H^{*}\left(\mathrm{H}_{2} \mathrm{O}, \mathrm{l}\right) \\
& -H\left(\mathrm{~s} \ln , \mathrm{nH}_{2} \mathrm{O}, \mathrm{A}, \mathrm{T}\right)+H^{*}(\mathrm{~A} .1 \mathrm{aq}, \mathrm{s})+(n-1) H^{*}\left(\mathrm{H}_{2} \mathrm{O}, 1\right) \\
& \Delta_{\mathrm{com}} H_{\mathrm{a}}=H^{*}(\mathrm{~A} .1 \mathrm{aq}, \mathrm{s})-H^{*}(\mathrm{~A}, \mathrm{~s})-H^{*}\left(\mathrm{H}_{2} \mathrm{O}, 1\right)
\end{aligned}
$$

\section{ENTHALPY OF SOLUTION}

It can be shown that the integral enthalpy of solution at saturation concentration of citric acid is given by

$$
\begin{aligned}
& \Delta_{\text {sat }} H_{\mathrm{d}}=(1-x)\left[\Delta_{\text {com }} H_{\mathrm{a}}+\Delta_{\mathrm{trs}} H_{\mathrm{g}}\right] \\
& \Delta_{\text {sat }} H_{\mathrm{d}}=(1-x)\left[\Delta_{\text {vap }} H_{\mathrm{i}}-\Delta_{\text {vap }} H_{\mathrm{h}}\right]
\end{aligned}
$$

and similarly for the hydrate

$$
\begin{aligned}
& \Delta_{\text {sat }} H_{\mathrm{c}}=(1-2 x) \Delta_{\text {com }} H_{\mathrm{a}}+(1-x) \Delta_{\mathrm{trs}} H_{\mathrm{g}} \\
& \Delta_{\text {sat }} H_{\mathrm{c}}=\Delta_{\text {sat }} H_{\mathrm{d}}-x \Delta_{\text {com }} H_{\mathrm{a}}
\end{aligned}
$$

\section{ENTHALPY OF TRANSITION}

The enthalpy change connected with the phase transition of eqn. $(\mathrm{g})$ is measured calorimetrically or evaluated from 


$$
\begin{aligned}
& \Delta_{\text {vap }} H_{\mathrm{b}} \stackrel{\prime}{-} \Delta_{\text {vap }} H_{\mathrm{h}}=+H^{*}\left(\mathrm{H}_{2} \mathrm{O}, \mathrm{v}\right)+H^{*}(\mathrm{~A}, \mathrm{~s})-H^{*}(\mathrm{~A}, 1 \mathrm{aq}, \mathrm{s}) \\
& -H^{*}\left(\mathrm{H}_{2} \mathrm{O}, \mathrm{v}\right)-x(1-x)^{-1} H^{*}(\mathrm{~A}, \mathrm{~s})+(1-x)^{-1} H(\mathrm{~s} \ln , \mathrm{A}, \mathrm{x}, \mathrm{T})
\end{aligned}
$$

$$
\begin{aligned}
\Delta_{\text {trs }} H_{\mathrm{g}}= & (1-2 x)(1-x)^{-1} H^{*}(\mathrm{~A}, \mathrm{~s}) \\
& +(1-x)^{-1} H(\mathrm{~s} \ln , \mathrm{A}, \mathrm{x}, \mathrm{T})-H^{*}(\mathrm{~A}, 1 \mathrm{aq}, \mathrm{s})
\end{aligned}
$$

Of course other combinations are possible, but we consider those given as the most relevant ones.

\section{EXPERIMENTAL EVALUATION}

The enthalpy changes corresponding to eqns. (e)-(g) are determined by calorimetry. Absolute entropies and entropy changes are evaluated from specific heat capacity measurements. The enthalpy changes corresponding to eqns. (b) and (h) are derived from the Clausius-Clapeyron law

$-\mathrm{R} \operatorname{dln}\left[p\left(\mathrm{H}_{2} \mathrm{O}\right) / p^{0}\right] / \mathrm{d}(1 / T)=\Delta_{\text {vap }} H$

In the treatment given above, it was assumed that all enthalpy values are determined at the same temperature. In practice, this will not be true and so we have to account for the temperature dependence of the enthalpy.

$\Delta H(T)=\Delta H\left(T_{0}\right)+\int_{T_{0}}^{T} \Delta C_{\mathrm{p}}(T) \mathrm{d} T$

In most cases, it will be accurate enough to use

$\Delta H(T)=\Delta H\left(T_{0}\right)+\overline{\Delta C_{\mathrm{p}}}\left(T-T_{0}\right)$

in which $\overline{\Delta C_{\mathrm{p}}}$ is the mean value in the temperature range $T-T_{0}$.

\section{SAMPLES}

Commercially available (Baker Analyzed, 99.8\%) citric acid monohydrate (formula mass 210.12) was used. Citric acid was prepared from the hydrate by prolonged heating and evacuation at $60^{\circ} \mathrm{C}$. From the mass loss, the ratio citric acid:water in the hydrate was found to be $1.00 \pm 0.005$.

\section{VAPOUR PRESSURE MEASUREMENTS}

These measurements were performed by a static method employing a diaphragm manometer (MKS Baratron Inc.) calibrated on a dead weight 
gauge (CEC). Temperature was measured with a platinum thermometer calibrated on IPTS-68 and accurate to within $0.01 \mathrm{~K}$. The experimental set-up has been described in detail previously [1]. The vapour pressure measurements as a function of temperature are fitted to the equation

$$
\begin{aligned}
R \ln \left(p / p^{0}\right)= & -\Delta G^{0}(\theta) / \theta+\Delta H^{0}(\theta)(1 / \theta-1 / T) \\
& +\Delta C_{\mathrm{p}}^{0}(\theta)\{\theta / T-1+\ln (T / \theta)\}
\end{aligned}
$$

in which $p^{0}$ is a standard pressure of $1 \mathrm{~Pa}, \theta$ is a reference temperature, usually mid-range, while the coefficients to be evaluated, $\Delta G^{0}, \Delta H^{0}$ and $\Delta C_{\mathrm{p}}^{0}$, are the thermodynamic function changes on vaporization.

\section{SOLUTION CALORIMETRY}

An isoperibol calorimeter was used. About $0.2 \mathrm{~g}$ of sample was dissolved in $100 \mathrm{ml}$ water. The corresponding enthalpy effect was evaluated from the measured temperature change and a separate specific heat determination.

Data were collected by a microcomputer and a correction for heat leak (heat leak constant $=-4.7 \times 10^{-5} \mathrm{~s}^{-1}$ ) was applied. The performance of the apparatus was checked by measuring the heat of solution of potassium chloride. From twenty measurements, a mean heat of solution of 17,34 \pm $0.035 \mathrm{~kJ} \mathrm{~mole}^{-1}$ was measured. This is in good accord with literature data of corresponding concentrations.

TABLE 1

Solubility, $x$, of citric acid monohydrate in water

\begin{tabular}{ll}
\hline$T(\mathrm{~K})$ & $x$ (mole fraction) \\
\hline 290.1 & 0.1123 \\
296.1 & 0.1233 \\
299.2 & 0.1354 \\
304.0 & 0.1488 \\
304.9 & 0.1501 \\
307.6 & 0.1559 \\
309.0 & 0.1636 \\
313.9 & 0.1750 \\
317.5 & 0.1860 \\
322.1 & 0.1923 \\
\hline
\end{tabular}




\section{SOLUBILITY}

The solubility of citric acid (monohydrate) in water was determined by putting together appropriate and precisely weighed amounts of the acid and water in a glass tube which was then sealed off. The glass tubes were rotated in a thermostat whose temperature was raised by approximately $1 \mathrm{~K}$ per day. The temperature at which the crystals are completely dissolved was taken as a point of the liquidus. The results are given in Table 1.

\section{POWDER X-RAY DIFFRACTION}

These measurements were made in the temperature range $32-38^{\circ} \mathrm{C}$ with a heating rate of $0.2 \mathrm{~K} \mathrm{ks}^{-1}$ and a film speed of $3 \mu \mathrm{m} \mathrm{s}^{-1}$. The diffraction pattern of the $\mathrm{Cu} K \alpha_{1}$ radiation was recorded on a Guinier-Simon camera (Enraf Nonius, The Netherlands). From the abrupt change in diffraction pattern, the transition temperature was evaluated.

\section{ADIABATIC CALORIMETRY}

The calorimeter used has been described before [2]; no alterations have been made.

\section{RESULTS AND DISCUSSION}

The molar heat capacity of citric acid monohydrate (sample mass $17.4095 \mathrm{~g}$ ) was measured under a helium pressure of about $200 \mathrm{~Pa}$. The measurements were made between 110 and $330 \mathrm{~K}$. The experimental results are given in Table 2 and the calculated thermodynamic values in Table 3. A large transition, which was slightly superheated, took place at $312.1 \mathrm{~K}$ (see Fig. 2). The heat capacity of the sample above the transition is very large and does show a large temperature dependence. The enthalpy of transition was calculated in the usual way by taking the enthalpy increment from 298 to $321 \mathrm{~K}$ and subtracting the heat capacity contribution. This heat capacity was linearly extrapolated to $312.1 \mathrm{~K}$ using the regions from 285 to $298 \mathrm{~K}$ and from 321 to $333 \mathrm{~K}$. The enthalpy of transition was $14.98 \mathrm{~kJ}^{\mathrm{mole}}{ }^{-1}$. After these measurements, the sample was cooled to $278 \mathrm{~K}$ and a cooling curve made. After several hours at $278 \mathrm{~K}$, a gradual exothermic effect took place which is quite different from the sudden crystallisation of a supercooled liquid. After two days, a new series of measurements was made. A significant 
TABLE 2

Experimental molar heat capacities, $C_{\mathrm{p}}$

\begin{tabular}{|c|c|c|c|c|c|c|c|}
\hline $\begin{array}{l}T \\
(\mathrm{~K})\end{array}$ & $\begin{array}{l}C_{\mathrm{p}} \\
\left(\mathbf{J} \mathbf{K}^{-1}\right. \\
\left.\text { mole }^{-1}\right)\end{array}$ & $\begin{array}{l}T \\
(\mathrm{~K})\end{array}$ & $\begin{array}{l}C_{\mathrm{p}} \\
\left(\mathrm{J}^{-1}\right. \\
\left.\text { mole }^{-1}\right)\end{array}$ & $\begin{array}{l}T \\
(\mathrm{~K})\end{array}$ & $\begin{array}{l}C_{\mathbf{p}} \\
\left(\mathbf{J}^{-1} \mathbf{K}^{-1}\right. \\
\left.\text { mole }^{-1}\right)\end{array}$ & $\begin{array}{l}T \\
(\mathrm{~K})\end{array}$ & $\begin{array}{l}C_{p} \\
\left(J K^{-1}\right. \\
\left.\text { mole }^{-1}\right)\end{array}$ \\
\hline
\end{tabular}

(a) Citric acid monohydrate

$\begin{array}{llllllll}118.23 & 126.79 & 190.46 & 183.38 & 245.09 & 225.29 & 291.86 & 262.21 \\ 123.81 & 131.25 & 194.67 & 186.23 & 248.69 & 228.16 & 295.05 & 264.31 \\ 129.24 & 135.63 & 198.82 & 189.61 & 252.26 & 231.06 & 298.21 & 267.36 \\ 134.53 & 139.90 & 202.92 & 192.33 & 255.79 & 233.77 & 301.34 & 271.02 \\ 139.69 & 144.09 & 206.96 & 195.67 & 259.30 & 236.62 & 304.44 & 275.35 \\ 144.74 & 147.92 & 210.97 & 198.56 & 262.77 & 239.52 & 307.50 & 282.28 \\ 149.68 & 151.76 & 214.93 & 201.83 & 266.21 & 241.71 & 310.48 & 301.15 \\ 154.53 & 155.73 & 218.83 & 205.17 & 269.63 & 244.55 & 316.22 & 406.97 \\ 159.28 & 159.24 & 222.70 & 207.76 & 273.02 & 247.38 & 318.58 & 399.46 \\ 163.96 & 163.07 & 226.53 & 210.83 & 276.37 & 249.91 & 320.88 & 406.27 \\ 168.55 & 166.64 & 230.32 & 213.63 & 279.70 & 252.15 & 323.16 & 413.19 \\ 173.06 & 170.12 & 234.07 & 216.66 & 283.01 & 254.77 & 325.40 & 419.78 \\ 177.51 & 173.73 & 237.78 & 219.54 & 285.42 & 256.71 & 327.62 & 426.56 \\ 181.88 & 176.90 & 241.45 & 222.60 & 288.66 & 259.19 & 329.80 & 434.56 \\ 186.20 & 180.14 & & & & & & \end{array}$

Second series

\begin{tabular}{rrrrrrrr}
288.74 & 258.18 & 303.82 & 279.68 & 316.47 & 403.41 & 324.73 & 418.76 \\
292.59 & 262.88 & 307.33 & 324.79 & 319.27 & 401.98 & 327.39 & 427.31 \\
296.39 & 267.70 & 309.77 & 788.29 & 322.03 & 410.34 & 330.01 & 436.40 \\
300.14 & 273.05 & & & & & & \\
(b) Citric acid & & & & & & \\
84.19 & 83.93 & 174.77 & 150.29 & 245.33 & 193.79 & 302.98 & 228.45 \\
94.47 & 93.34 & 181.67 & 154.61 & 257.16 & 201.16 & 305.66 & 230.30 \\
104.04 & 100.76 & 188.46 & 158.94 & 262.94 & 204.57 & 308.32 & 231.21 \\
113.07 & 107.53 & 195.14 & 163.34 & 268.66 & 208.19 & 310.98 & 233.36 \\
121.67 & 114.05 & 201.71 & 167.50 & 276.69 & 213.03 & 313.63 & 234.69 \\
129.94 & 120.25 & 208.17 & 171.45 & 282.27 & 216.44 & 316.28 & 235.92 \\
137.92 & 125.55 & 214.55 & 175.43 & 287.79 & 219.05 & 318.91 & 237.36 \\
145.67 & 130.66 & 220.84 & 179.01 & 293.27 & 222.75 & 321.54 & 239.20 \\
153.19 & 136.46 & 227.05 & 182.95 & 298.71 & 225.99 & 324.15 & 241.22 \\
160.54 & 141.29 & 233.18 & 186.44 & 297.59 & 224.80 & 326.76 & 242.32 \\
167.73 & 146.04 & 239.34 & 190.31 & 300.29 & 226.75 & 329.35 & 244.23 \\
\hline
\end{tabular}

difference in the heat capacity prior to the transition and a lower enthalpy of transition (including the larger pre-effect) of $14.47 \mathrm{~kJ} \mathrm{~mole}^{-1}$ were found, indicating that the formation of the monohydrate from the high-temperature 
TABLE 3

Calculated thermodynamic values of citric acid monohydrate

\begin{tabular}{llcll}
\hline $\begin{array}{l}T \\
(\mathrm{~K})\end{array}$ & $\begin{array}{l}C_{\mathrm{p}} \\
\left(\mathbf{J ~ K ~ K}^{-1} \text { mole }^{-1}\right)\end{array}$ & $\begin{array}{l}G-G(0) \\
\left(\mathrm{J} \mathrm{mole}^{-1}\right)\end{array}$ & $\begin{array}{l}H-H(0) \\
\left(\mathrm{J} \mathrm{mole}^{-1}\right)\end{array}$ & $\begin{array}{l}S-S(0) \\
\left(\mathrm{J} \mathrm{K} \mathrm{K}^{-1} \text { mole }^{-1}\right)\end{array}$ \\
\hline 120 & 128.14 & -5728 & 7849 & 113.14 \\
130 & 136.28 & -6913 & 9171 & 123.72 \\
140 & 144.28 & -8202 & 10574 & 134.11 \\
150 & 152.18 & -9594 & 12056 & 144.34 \\
160 & 159.98 & -11098 & 13617 & 154.41 \\
170 & 167.70 & -12682 & 15255 & 164.34 \\
180 & 175.37 & -14375 & 16971 & 174.14 \\
190 & 183.00 & -16165 & 18763 & 183.83 \\
200 & 190.69 & -18051 & 20631 & 193.41 \\
210 & 198.20 & -20032 & 22575 & 202.89 \\
220 & 205.82 & -22108 & 24585 & 212.29 \\
230 & 213.47 & -24278 & 26691 & 221.60 \\
240 & 221.18 & -26540 & 28864 & 230.85 \\
250 & 228.95 & -28895 & 31115 & 240.04 \\
260 & 236.81 & -31341 & 33444 & 249.17 \\
270 & 244.78 & -33878 & 35851 & 258.26 \\
280 & 252.88 & -36506 & 38340 & 267.30 \\
290 & 261.12 & -39224 & 40900 & 276.32 \\
300 & 269.52 & -42032 & 43562 & 285.32 \\
\hline
\end{tabular}

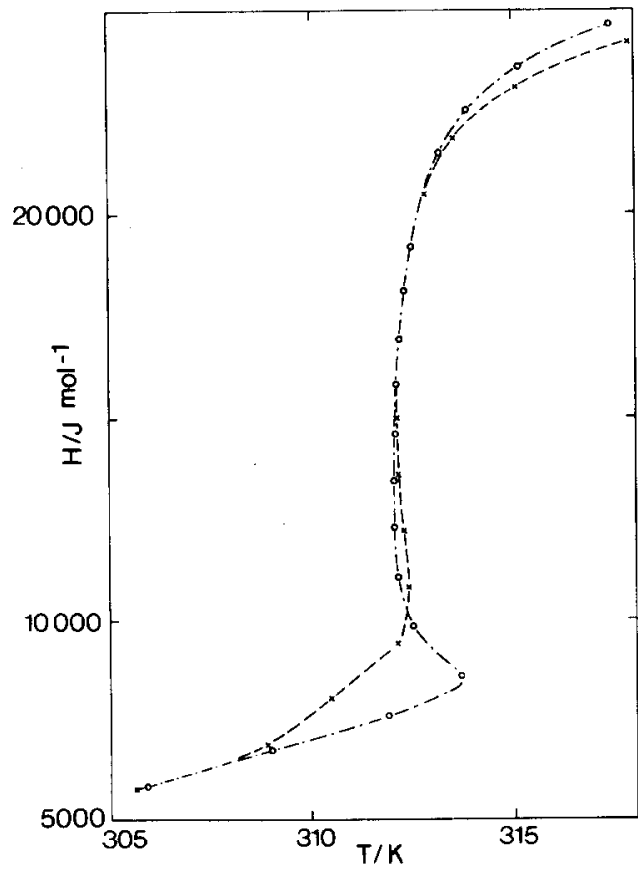

Fig. 2 . The enthalpy curve by adiabatic calorimetry. $O=$ first series; $x=$ second series. 
phase was not complete. In this second measurement, the superheating of the transition was only about $0.1 \mathrm{~K}$.

For citric acid, a sample of $8.0608 \mathrm{~g}$ was used. Helium gas was admitted to a pressure of $200 \mathrm{~Pa}$. Measurements were made between 80 and $330 \mathrm{~K}$. As no specific heat anomaly was found in the region where the monohydrate has its transition, it is safe to assume that no hydrate was present. The experimental results are also given in Table 2, and the calculated thermodynamic values and the smoothed heat capacity values from $90 \mathrm{~K}$ are given in Table 4. Specific heat measurements of the monohydrate have been reported by Evans et al. [3] ranging from 10 to $298 \mathrm{~K}$. Comparing our data from 90 to $298 \mathrm{~K}$ shows no significant difference. Our data measured with automated apparatus are more smooth, but the overall difference in enthalpy increment

\section{TABLE 4}

Calculated thermodynamic values of citric acid

\begin{tabular}{|c|c|c|c|c|}
\hline $\begin{array}{l}T \\
(\mathrm{~K})\end{array}$ & $\begin{array}{l}C_{\mathrm{p}} \\
\left(\mathrm{J} \mathrm{K}^{-1} \mathrm{~mole}^{-1}\right)\end{array}$ & $\begin{array}{l}G-G(90) \\
\left.\mathrm{J} \text { mole }^{-1}\right)\end{array}$ & $\begin{array}{l}H-H(90) \\
\left(\mathrm{J} \mathrm{mole}^{-1}\right)\end{array}$ & $\begin{array}{l}S-S(90) \\
\left(\mathrm{J} \mathrm{K}^{-1} \mathrm{~mole}^{-1}\right)\end{array}$ \\
\hline 90 & 90.03 & 0 & 0 & 0.00 \\
\hline 100 & 97.79 & -50 & 939 & 9.89 \\
\hline 110 & 105.36 & -198 & 1955 & 19.57 \\
\hline 120 & 112.74 & -441 & 3045 & 29.05 \\
\hline 130 & 119.94 & -778 & 4209 & 38.36 \\
\hline 140 & 126.98 & -1207 & 5444 & 47.51 \\
\hline 150 & 133.87 & -1728 & 6748 & 56.50 \\
\hline 160 & 140.62 & -2337 & 8121 & 65.36 \\
\hline 170 & 147.24 & -3034 & 9560 & 74.08 \\
\hline 180 & 153.74 & -3818 & 11065 & 82.68 \\
\hline 190 & 160.13 & -4688 & 12634 & 91.17 \\
\hline 200 & 166.43 & -5641 & 14267 & 99.54 \\
\hline 210 & 172.64 & -6678 & 15963 & 107.81 \\
\hline 220 & 178.78 & -7797 & 17720 & 115.99 \\
\hline 230 & 184.85 & -8998 & 19538 & 124.07 \\
\hline 240 & 190.87 & -10278 & 21417 & 132.06 \\
\hline 250 & 196.85 & -11639 & 23355 & 139.98 \\
\hline 260 & 202.80 & -13078 & 25353 & 147.81 \\
\hline 270 & 208.73 & -14595 & 27411 & 155.58 \\
\hline 280 & 214.65 & -16189 & 29528 & 163.27 \\
\hline 290 & 220.57 & -17860 & 31704 & 170.91 \\
\hline 300 & 226.51 & -19607 & 33940 & 178.49 \\
\hline 310 & 232.48 & -21430 & 36234 & 186.01 \\
\hline 320 & 238.48 & -23327 & 38589 & 193.42 \\
\hline 330 & 244.53 & -25299 & 41004 & 200.92 \\
\hline
\end{tabular}


in this region is only $18 \mathrm{~J}$ mole $^{-1}$ or less than $0.05 \%$ of the total effect. Table 3 is calculated by using the Evans values for the absolute entropy and the enthalpy at $120 \mathrm{~K}$. No measurements of the heat capacity of the monohydrate above $298 \mathrm{~K}$ or of citric acid have been reported before.

The experimentally measured vapour pressures over the hydrate and the saturated solution are given in Table 5. After pumping a few seconds at the hydrate sample, it took several hours before the equilibrium pressure was re-established. Therefore the scatter in these data is much higher than in those of the saturated solution for which equilibrium was established in a few minutes. When the saturated solution was cooled well below the transition temperature, vapour pressures were not initially constant and were well above the equilibrium values. Only after several days equilibrium were they re-established, indicating again the slow equilibration mechanism as observed in adiabatic calorimetry. The result of fitting the experimental vapour pressure data to eqn. (12) is given in Table 6.

From the intersection of the two vapour pressure lines, the transition temperature is found to be $309.5 \pm 0.5 \mathrm{~K}$. The X-ray powder diffraction patterns give a transition temperature of $309.0 \pm 0.5 \mathrm{~K}$. This is compared

\section{TABLE 5}

Experimental water vapour pressures above citric acid monohydrate and above a saturated solution

\begin{tabular}{|c|c|c|c|c|c|}
\hline \multicolumn{3}{|c|}{ Citric acid monohydrate } & \multicolumn{3}{|c|}{ Saturated solution } \\
\hline $\begin{array}{l}T \\
(\mathrm{~K})\end{array}$ & $\begin{array}{l}P \\
(\mathrm{~Pa})\end{array}$ & $100^{*} \Delta \ln P^{*}$ & $\begin{array}{l}T \\
(\mathrm{~K})\end{array}$ & $\begin{array}{l}P \\
(\mathrm{~Pa})\end{array}$ & $100^{*} \Delta \ln P^{*}$ \\
\hline 278.10 & 325.00 & -2.01 & 309.77 & 4141.00 & -0.40 \\
\hline 282.88 & 521.00 & 2.40 & 314.78 & 5414.00 & 1.89 \\
\hline 289.11 & 893.00 & 3.14 & 316.95 & 5773.00 & -1.92 \\
\hline 293.12 & 1212.00 & 0.95 & 321.87 & 7311.00 & -0.73 \\
\hline 293.75 & 1213.00 & -4.01 & 322.89 & 7756.00 & 0.64 \\
\hline 297.67 & 1748.00 & 1.77 & 329.30 & 10109.00 & -0.18 \\
\hline 298.42 & 1760.00 & -3.34 & 330.09 & 10645.00 & 1.73 \\
\hline 301.99 & 2332.00 & -2.17 & 338.01 & 14368.00 & 0.53 \\
\hline 303.23 & 2582.00 & -1.18 & 342.22 & 16609.00 & -0.59 \\
\hline 306.15 & 3240.00 & 0.23 & 342.31 & 16662.00 & -0.58 \\
\hline 306.17 & 3399.00 & 4.78 & 342.27 & 16530.00 & -1.26 \\
\hline 306.42 & 3373.00 & 2.35 & 351.77 & 23346.00 & 0.39 \\
\hline 308.96 & 3902.00 & -1.20 & 351.81 & 23333.00 & 0.20 \\
\hline 309.06 & 3906.00 & -1.77 & 351.84 & 23386.00 & 0.31 \\
\hline
\end{tabular}

* The residuals are calculated from eqn. (12) and the coefficients given in Table 6. 


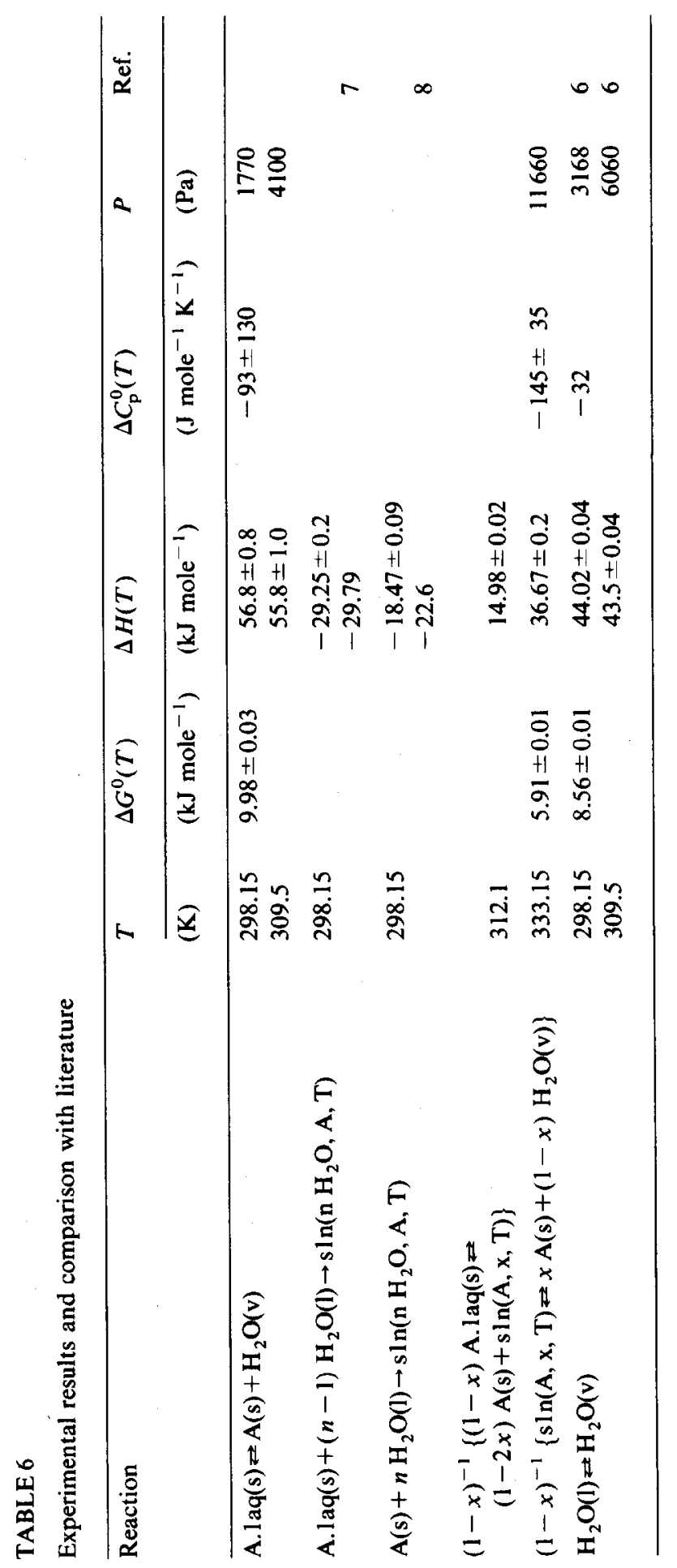


with a literature value of $309.7 \mathrm{~K}[4,5]$. The transition temperature found with the adiabatic calorimeter is $312.1 \mathrm{~K}$. Although a temporary superheating of $1.5 \mathrm{~K}$ is observed, it is not clear where this discrepancy originates, particularly as we have used extremely low heating rates comparable with those of the X-ray powder diffraction experiments. For further calculation, we will adopt a transition temperature of $309.5 \mathrm{~K}$.

The heats of solution of the hydrate and of the anhydrate were each determined eight times. In Table 6 we give the experimental results and literature values.

The values of pure water have been taken from ref. 6. Employing eqns. (2) and (3), we find for the enthalpy of compound formation as defined by eqn. (a) from vapour pressure measurements $\Delta_{\text {com }} H_{\mathrm{a}}(298.15 \mathrm{~K})=-12.8 \pm 1 \mathrm{~kJ}$ mole $^{-1}, \Delta_{\text {com }} H_{\mathrm{a}}(309.5 \mathrm{~K})=-12.3 \pm 1 \mathrm{~kJ} \mathrm{~mole}^{-1}$ and $\Delta_{\text {com }} H_{\mathrm{a}}(298.15 \mathrm{~K})=$ $-10.8 \pm 0.6 \mathrm{~kJ} \mathrm{~mole}^{-1}$ from solution calorimetry. The enthalpy of transition defined by eqns. $(\mathrm{g})$ and $(8)$ is found to be $\Delta_{\mathrm{trs}} H_{\mathrm{g}}(309.5 \mathrm{~K})=15.69 \pm 1 \mathrm{~kJ}$ mole ${ }^{-1}$ and $\Delta_{\text {trs }} H_{\mathrm{g}}(312.1 \mathrm{~K})=14.98 \pm 0.2 \mathrm{~kJ}$ mole ${ }^{-1}$ from vapour pressure measurements and adiabatic calorimetry, respectively.

For equilibrium (b), from the values in Table 6 we calculate $\Delta_{\text {vap }} S_{\mathrm{b}}^{0}$ $(298.15 \mathrm{~K})=157.21 \pm 2.7 \mathrm{~J} \mathrm{~K}^{-1} \mathrm{~mole}^{-1}$.

Using the absolute entropies of the monohydrate and water vapour, we calculate the absolute entropy of citric acid as $S^{0}(\mathrm{~s}, 298.15 \mathrm{~K})=252.1 \mathrm{~kJ}^{-1}$ mole $^{-1}$. The relative value $S^{0}(\mathrm{~s}, 298.15 \mathrm{~K})-S^{0}(\mathrm{~s}, 90 \mathrm{~K})=177.1 \mathrm{~J} \mathrm{~K}^{-1}$ $\mathrm{mole}^{-1}$. Therefore to convert the entropy values in Table 4 to absolute values they must be increased by $75 \mathrm{~J} \mathrm{~K}^{-1}$ mole $^{-1}$. So, $S^{0}(\mathrm{~s}, 90 \mathrm{~K})=75 \mathrm{~J} \mathrm{~K}^{-1}$

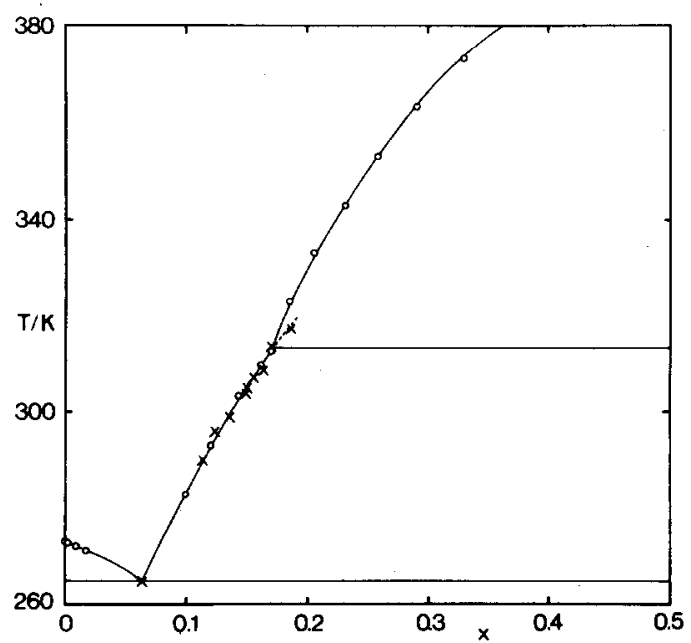

Fig. 3. The experimental phase diagram between $x=0$ (water) and $x=0.5$ (the hydrate). $\mathrm{O}=$ literature data; $x=$ our measurements. 
mole ${ }^{-1}$. Of course several other thermodynamic quantities of the system citric acid-water can be calculated with the results presented here and making use of the consistent set of phase transition equations given above. We think that those given are the most interesting and useful ones.

Finally, we give in Fig. 3 the binary $T-x$ phase diagram based on both our measurements and literature values.

\section{REFERENCES}

1 C.G. de Kruif, T. Kuipers, J.C. van Miltenburg, R.C.F. Schaake and G. Stevens, J. Chem. Thermodyn., 13 (1981) 1081.

2 R.C.F. Schaake, J.C.A. Offringa, G.J.K. van den Berg and J.C. van Miltenburg, Rec. Trav. Chim. Pays-Bas, 98 (1979) 408.

3 D.M. Evans, F.E. Hoare and T.P. Melia, Trans. Faraday Soc., 58 (1962) 1511.

4 Kirk-Othmer, Encyclopedia of Chemical Technology, Wiley, New York, 1978.

5 J.L. Marshall, J. Proc. Aust. Chem. Inst., 5 (1938) 383.

6 R.A. Robie, B.S. Hemingway and J.R. Fisher, Thermodynamic Properties of Minerals. U.S. Government Printing Office, Washington, 1978.

7 B.J. Levin, J. Phys. Chem., 59 (1955) 640.

8 International Critical Tables of Numerical Data. Vol. V, McGraw-Hill, New York, 1929. 